\title{
A Critical Study of the Problems Faced by the Libyan Students in Reading and Comprehension of English as a Foreign Language
}

\author{
Hakeem M. Elmadwi, Dr. Ritu Shepherd \\ Research Scholar in English and Foreign Languages, Faculty of Humanities Social Sciences and Education, \\ Sam Higginbottom Institute of Agriculture Technology and Sciences ( Formerly Allahabad Agriculture Institute \\ )- Deemed University, Allahabad \\ Assistant Professor, in English and Foreign Languages, Faculty of Humanities Social Sciences and Education, \\ Sam Higginbottom Institute of Agriculture Technology and Sciences ( Formerly Allahabad Agriculture Institute \\ )- Deemed University, Allahabad
}

\begin{abstract}
This study was conducted with the participation of the students in the English Department at the University of Zawia, Libya. This study is designed to explore the reading strategy most often used among Libyan university students, to show how male and females use learning strategies when they face a text in English, and also to show the relationship between the learners' strategies use and their EFL proficiency. The results of the study show that the most frequently Reading strategies used was meta-cognitive strategies, there is a statistically differences between male and female learners in their use of language learning strategies. Furthermore, the results also show differences between students' level of proficiency and their use of language learning strategies.
\end{abstract}

Key words: Language Learning, Learning strategy, Libyan EFL Learning, gender, and academic level

\section{Introduction:}

In Libya, English is taught as a foreign language, and the purpose of learning English is for communication and to communicate efficiently. Learners need the four skills that are listening, speaking, reading, and writing. But of all these four skills, reading plays a vital role for students in the classroom. Therefore, the ability to read is considered the most firm, tough, and most important skill. This specific difficulty in learning to read was first observed by and documented in the early half of the last century by Hinshelwood (1917). According to Carrell (2006), "effective reading in a second language is critical for students in English as a Foreign Language context, at an advanced level of proficiency or with a need for English Academic Purpose". From personal point of view, which has developed out of my three years experience as a teacher of EFL and a teaching assistant of EFL, EFL teacher's practices in Libya schools are far from teaching reading skills and strategies. Rather, EFL teachers spend the time devoted for reading in practicing only one skill, "silent reading". And on what they believe are "comprehension questions". Because of this huge gap between the world's rapid movement toward teaching reading skills and strategies and the reality of reading instruction in Libya, because of this thought, and according to my experience as an EFL teacher, I think most second language learners at Libyan University Schools encounter problems in learning reading. A lot of researchers and teachers have tried to discover possible methods to help students read successfully in English. There are many factors which affect the reading proficiency of a second language. Some of these factors are text types, school and social environments, students' intelligence, learning motivation, teaching methods, learning strategies and so on.

I believe learning strategies are the most important factor. Therefore, I am conducting this study to explore the reading strategies most often used among Libyan university students, to show how males and females use learning strategies when they face a text in English, and also to show the relationship between the learners' strategies use and their EFL proficiency. And to do so, I will use a Reading Strategy Questionnaire to measure Reading Strategy Use and a Reading Comprehension Test to measure learners' EFL proficiency.

\section{Objectives of the Study:}

$>$ To show the type of strategies which most students apply in reading and comprehension of English as a foreign language and to point up the most often strategy used among the learners in this study?

$>$ To show the relationship between gender and reading comprehension.

$>$ To show the relationship between students' level of proficiency and their use of the reading strategies.

\section{Hypothesis of the Study:}


$\checkmark \quad$ There will be no statistically differences between the uses of the language learning strategies.

$\checkmark$ There will be no statistically differences between males and females in their use of the language learning strategies.

$\checkmark \quad$ There will be no statistically differences between low and high proficient EFL learners in their use of the language learning strategies.

\section{Second / Foreign Language Reading}

For many people, reading is the most important of the four skills in a second language, especially in English as a second and foreign language. According to Carrell (2006), effective reading in a second language is critical for students in EFL context, at an advanced level of proficiency, or with a need for English for Academic purposes. For a long time, EFL reading was viewed as a rather passive, bottom-up process. In other words we can say, EFL reading was primarily a decoding process of reconstructing the author's intended meaning through identifying the printed letters and words and building up a meaning for a text from the smallest textual units at the "bottom" ( letters and words) to larger units at the "top" ( phrases and clauses). Bacon (1990) states that, reading is an important process and reading skills are probably the most important skills required for academic and professional purposes.

\section{Language Learning Strategies}

Research has proved that language learning strategies are extremely effective in second or foreign language learning; they have the potential to be "an extremely powerful learning tool" (O'Mally, Chamot, Stewner-Manzanares, Kuper, and Russo, 1985, P. 43). In 1985, O’Mally et al. all defined learning strategies as being "operations or steps used by a learner that will facilitate the acquisition storage, retrieval or use of information" (p. 23). In 1986, Weinsten and Mayer stated that learning strategies have learning facilitation as a goal and are intentional on the part of the learner. In fact, more proficient students tend to consciously use more strategies to learn the language (O'Mally \& Chamot, 1990; Oxford, 1999). In 1990(b), Oxford stated that "learning strategies are specific actions taken by the learner to make learning easier, faster, more enjoyable, more self-directed, more effective, and more transferable to new situations" (p. 8). Oxford classified learning strategies into six groups: memory-related, cognitive, compensation, meta-cognitive, affective, and social strategies. The classification framework of learning strategies came into being from some researchers' efforts for determining the characteristics of the "good language learner" (Naiman et al. 1978; Rupin 1975; Stern, 1975). Oxford's taxonomy is "perhaps the most comprehensive classification of learning strategies to date" (Ellis, 1994, p. 539). In Oxford's language learning strategies taxonomy, language-learning strategies are divided into two big categories: direct and indirect strategies. According to Oxford (1990b, p. 71), the direct language learning strategies is "directly involve the subject matter". In that sense, "all direct strategies require mental processing of the language" (Oxford, 1990b, p 37). As for the indirect language learning strategies, they "don not directly involve the subject matter itself, but are essential to language learning nonetheless" (Oxford, 1990b, p. 71). The category of direct strategies is further divided into three subcategories, including memorystrategies, cognitive strategies, and compensation strategies. Similar to direct strategies, the category of indirect strategies is also divided into three categories, including meta-cognitive strategies, affective strategies, and social strategies

\section{Gender and L2 Reading}

As gender is an issue with important theoretical and pedagogical implications in second language learning, it has received some attention in language learning strategy research (e.g., Oxford, 1993, Oxford, Young, Ito and Sumrall, 1993; Oxford, 1995; Young and Oxford 1997). These studies have found that gender differences proposes that although sometimes males suppressed females in the use of a particular strategy, females employ more learning strategies or employ strategies more effectively (Erhman and Oxford, 1989; Nayikos, 1990: Oxford, 1994; Sheorey, 1999). Oxford and Naykos (1989) who looked at strategies used by 1200 university students concluded that gender differences had a "profound influence" (p.296) on strategy use, and that females used strategies more frequently than males.

\section{Samples of the study:}

\section{Methodology of the Study}

The participants of this study will be one hundred twenty Libyan students from Zawia University located in the West part of Libya (120 km west the capital Tripoli). This number of the participants will be chosen randomly. The age of the participants is between 18-24 years old. The gender of the participants is heterogeneous (males $60(50 \%)$ and females $60(50 \%)$ ). 


\section{Procedures of the study:}

In this study, I am going to use a quantitative research. Data collection methods for this study will involve two techniques; a test and a questionnaire for students.

In this study, T-tests and SPSS will help in actual data calculation.

\section{Research Questions}

This study is designed to explore three things: the use of reading strategies among Libyan EFL collegelevel-learners; the relationship between strategy use and Libyan EFL reading comprehension; and the relationship between reading strategies and gender. So, this study will answer the following questions:

1- What language learning strategies do Libyan EFL learners in Libyan Universities report using? And what are their most frequently used language learning strategies?

2- Does gender play an important role in reading strategies use and reading proficiency?

3- Is there a relationship between the readers' strategies used and their EFL proficiencies?

\section{Data analysis Procedures}

The background Reading Strategy Questionnaire (RSQ) and the Reading Comprehension Test were distributed to regular classes of the third year EFL students of Zawia University (college of Arts Zwara, college of Arts Sabratha, and College of Education) during the regular class meeting. The class instructor, who was informed about the nature of the Reading Strategy Questionnaire and the Reading Comprehension Test, supervised the distribution process. The Reading Comprehension Test took an average of forty five (50) minutes to finish under a complete condition of confidentiality. The Reading Strategy Questionnaire took thirty minutes as well to finish. A total of 120 Questionnaire were answered completely out of 150 distributed ones. All 120 Reading Comprehension Test were answered completely. All Reading Strategy Questionnaires that were not fully answered were disregarded.

Data analysis was carried out using the SPSS (Statistical Package for the Social Science) version 19 to score the data and answers the research questions, in order to obtain descriptive statistics. First, Means, Standard Deviations, and Frequencies of data were computed to summarize the learners' responses to the Reading Strategy Questionnaire (RSQ) with a view to presenting the strategy use of the Libyan EFL learners and hence to answer the first research question. Then, to determine any variations in strategy use due to gender, and English proficiency, several analyses of variance (ANOVA) were conducted to determine whether there were any statistical differences among learners with regard to strategy use. NPar Tests (Mann-Whitney Test) were used to determine any variations in strategy use due to gender and hence to address the second research question. Finally, for learners' Reading Comprehension Test scores, a visual banner features in SPSS was utilized to determine the differences of mean scores of strategy use among learners at different academic levels. Participants who scored between 2 and 14 were considered low level, between 15 and 20 were considered medium level, and between 20 and 30 were considered high level of comprehension.

\section{Results}

What language learning strategies do Libyan EFL learners in Libyan Universities report using? And what are their most frequently used language learning strategies?

The descriptive statistics regarding the mean scores on individual reading strategy use are shown in table (1). The most frequent use of reading strategy was meta-cognitive strategy $(\mathrm{M}=22.2500, \mathrm{SD}=3.35$ ), followed by compensation strategy $(M=21.8929, S D=2.98)$, followed by affective strategy $(M=20.0973$, SD $=3.22)$, followed by cognitive strategy $(\mathrm{M}=18.2162, \mathrm{SD}=3.00)$, followed by memory strategy $(\mathrm{M}=17.8571$, $\mathrm{SD}=3.39)$, and then followed by social strategy upside down $(\mathrm{M}=15.009$, SD 2,23) which is the least frequently used strategies.

As shown in Table (1), the mean values for the strategy use ranged from 15.009 to 22.2500 . These findings were consistent with the results, showing medium usage of language learning strategy by Libyan learners. As seen in Table (1), the overall mean score of six learning strategies demonstrate that the participants of the study were medium strategy users $(M=19.2357)$. This finding was consistent with the results of related studies conducted by Shr-Chau Huang, I-Chen Chen, and Feng Fang Li (2004), Chang-Ching Yi \& Liu, ShuChen \& Lee, Yi-Nian (2007), and Pezhman Zare (2010), showing medium usage of learning strategies by Libyan, Taiwanese, Iranian, and Chinese students respectively.

Pertaining to six categories of strategies, table (1) shows that Libyan EFL learners used Meta-cognitive Strategies more frequently $(M=22.2500)$ than other categories of strategies. This finding is supported by the result of relevant research studies conducted on EFL learners from Iran (2004, Mohammad Rahimi, Abdolmehdi Raizi, and Sharazad Siaf), Iran (2011, Masoud Hashemi), and Taiwan (2004, Shra-Chau Huang, I-Chen Chen). 
Table (1) Mean scores of language reading strategies

\begin{tabular}{|l|l|l|l|}
\hline & Mean & Std. Deviation & Rank \\
\hline Memory & 17.8571 & 3.39012 & 5 \\
\hline Cognitive & 18.2162 & 3.00728 & 4 \\
\hline Compensation & 21.8929 & 2.98753 & 2 \\
\hline Metacognitive & 22.2500 & 3.25175 & 1 \\
\hline Affective & 20.0973 & 3.22647 & 3 \\
\hline Social & 15.1009 & 2.23584 & 6 \\
\hline Overall mean & 19.2357 & & \\
\hline
\end{tabular}

Does gender play an important role in reading strategies use and reading proficiency?

As shown in Table (2), meta-cognitive strategies $(\mathrm{M}=22.5690, \mathrm{SD}=3.19601)$ were the most frequently used strategies by female learners, followed by compensation strategies $(\mathrm{M}=22.0172, \mathrm{SD}=3.33241)$, affective strategies $(M=21.0508, \mathrm{SD}=3.03101)$, memory strategies $(\mathrm{M}=18.60000, \mathrm{SD}=3.62290)$, cognitive strategies $(M=18.0000, S D=2.17830)$, whereas the least preferred categories were social strategies $(M=15.5965, S D=$ 2.17830).

Table (2) Gender differences in Means of Strategy Use (FEMALE LEARNERS)

\begin{tabular}{|l|l|l|l|l|l|}
\hline Strategy & $\mathrm{N}$ & Mean & Std. Deviation & Std. Error Mean & Rank \\
\hline Memory & 60 & 18.6000 & 3.62290 & .46771 & 4 \\
\hline Cognitive & 58 & 18.0000 & 2.94987 & .38734 & 5 \\
\hline Compensation & 58 & 22.0172 & 3.33241 & .43757 & 2 \\
\hline Meta-cognitive & 58 & 22.5690 & 3.19601 & .41966 & .39460 \\
\hline Affective & 59 & 21.0508 & 3.03101 & .28852 & 3 \\
\hline Social & 57 & 15.5965 & 2.17830 & 1.60145 & 6 \\
\hline Overall strategy & 52 & 117.8269 & 11.54823 & & \\
\hline
\end{tabular}

As the case for male learners as shown in table (3), meta-cognitive strategies $(\mathrm{M}=21.9074, \mathrm{SD}=$ $3.50885)$, were the most frequently used strategies, followed by compensation strategies $(\mathrm{M}=21.7593, \mathrm{SD}=$ 2.59124), affective strategies $(M=19.0556, S D=3.13481)$, cognitive strategies $(M=18.4528, S D=3.07950)$, memory strategies $(M=17.0000, S D=2.90368)$, and social strategies $(M=14.5577, S D=2.19101)$ were used with least frequency.

Table (3) Gender Differences in Means of Strategies Use (MALE LEARNERS).

\begin{tabular}{|l|c|c|c|c|c|}
\hline Strategy & N & Mean & Std. Deviation & Std. Error Mean & Rank \\
\hline Memory & 52 & 17.0000 & 2.90368 & .40267 & 5 \\
\hline Cognitive & 53 & 18.4528 & 3.07950 & .42300 & .35262 \\
\hline Compensation & 54 & 21.7593 & 2.59124 & .47749 & \\
\hline Meta-cognitive & 54 & 21.9074 & 3.50885 & .42659 & 1 \\
\hline Affective & 54 & 19.0556 & 3.13481 & .30384 & 3 \\
\hline Social & 52 & 14.5577 & 2.19101 & 1.31541 & 6 \\
\hline Overall strategy & 49 & 112.9184 & 9.20787 & & \\
\hline
\end{tabular}

Mann-Whiteney Tests were used to find out the differences between male and female EFL learners in the use of learning strategies. With regard to the overall strategy use, females are considered to be high strategy users, while their counterparts, males, demonstrated medium strategy usage. This indicated that female learners in the sample reported higher overall mean use of strategies than male learners (female mean=117.8269 VS male mean=112.9184).

Is there a relationship between the readers' strategies used and their EFL proficiencies?

Table (4) Distribution of the male learners according to their Reading Comprehension Test scores

\begin{tabular}{|c|c|c|}
\hline \multicolumn{3}{|c|}{ MALES } \\
\hline LEVEL OF COMPREHNSION & FREQUENCY & PERCENT \\
\hline LOW $2-14$ & 36 & $60 \%$ \\
\hline MEDIUM $15-20$ & 16 & $26 \%$ \\
\hline HIGH 21-30 & 08 & $13 \%$ \\
\hline TOTAL & 60 & $100 \%$ \\
\hline
\end{tabular}

As shown in Table (4), male learners placed in the low level scored 60\%, while medium level learners score $26 \%$, and followed by high level learners $13 \%$. 
Table (5) Distribution of the female learners according to their Reading Comprehension Test scores

\begin{tabular}{|c|c|c|}
\hline \multicolumn{2}{|c|}{ FEMALES } & PERCENT \\
\hline LEVEL OF COMPREHNSION & FREQUENCY & $38 \%$ \\
\hline LOW 2-14 & 23 & $36 \%$ \\
\hline MEDIUM 15-20 & 22 & $25 \%$ \\
\hline HIGH 21-31 & 15 & $100 \%$ \\
\hline TOTAL & 60 & \\
\hline
\end{tabular}

Table (5), shows the results of female learners in their Reading Comprehension Test. Low learners scored 38\%, whereas medium level learners scored $36 \%$, and finally high level learners scored $25 \%$.

The outcomes of the tables above show that there is a relationship between female and male learners in their Reading Comprehension Test scores and their reading strategies use. Female learners were considered high strategy users, while male learners were considered low range users.

\section{Conclusion}

This study tried to examine the Language Learning Studies of Libya EFL learners at the University of Zawia. The study results indicate that Libyan university learners' English learning strategy usage at a medium range (19.2357). Among them, meta-cognitive strategies were used more frequently $(M=22.2500)$ than other types of strategies. When male and female learners were compared, the female learners tend to pick up strategies at their EFL classes more than male learners. As in the case of learners' EFL proficiency level, female learners also showed a higher performance of comprehension and indicted a higher level of EFL proficiency.

\section{References}

[1] Hinshelwood, J . (1917). Congenial Word Business. London, Lewis.

[2] Carrell, P. L. (2006). Introduction: Interactive Approaches to Second Language Reading, Interactive Approaches to Second Language Reading, ed. by P. L. Carrell, J. Devine, \& D. E. Eskey, Cambridge University Press, New York, , pp. 1-7.

[3] Bacon, S. M., (1990). A Study of the Attitudes, Motives, and Strategies of University Foreign Language Students and their Disposition to Authentic oral and Written Input. Modern Language Journal, 74, 459-473.

[4] O’Malley, Chamot, Stewner-Manzanares, Kuper. L \& Russo, R. (1985). Learning Strategies Applications with students of English as a Second Language. TESOL Quartely, 19, 285-296.

[5] Weinsten, C. E., and Mayer, R. E. (1986). The Teaching of Learning Strategies. in m. c. Wittrock (ed.), Handbook of Research on Teaching ( $3^{\text {rd }}$ ed. pp. 315-27). ny: Macnillian.

[6] O'malley, J.M. \& Chamot, A.U., (1990). Learning Strategies in Second Language Acquisition. Cambridge, U.K.: Cambridge university press.

[7] Oxford, r. 1. (1990). language learning strategies: what early teacher should know. Boston: Heinle \& heinle.

[8] Naiman et al (1978). The Good Language Lewarner.Toronto: Ontario institute for studies in education.

[9] Rubin, S. J. (1975). What the Good Language Teacher can Teach us. TESOL Quarterly, 9, 41-51.

[10] Stern, H. H. (1975). what we can learn from the good language learner?. Canadian Modern review, 31, $304-18$

[11] Ellis, R., (1994). Understanding Second Language Acquisition. Oxford: Oxford University Press.

[12] Oxford, R. L. (1993). Instructional Implications of Gender Differences in Language Learning Styles and Strategies. Applied Language Learning, 4, 65-94.

[13] Oxford et al. (1993). Language Learning Strategies, Attitudes, Motivation, and Self-Image of Students in a University Intensive ESL Program. Paper presented at the Annual Convention of Teachers of English to Speakers of other Languages, San Fransisco.

[14] Young \& Oxford, R. L. (1997). Effect of Sex Differences, Career Choice, and Psychological Type on Adults' Language Learning Strategies. Modern Language Journal, 73 (1), 1-13.

[15] Erhman and Oxford, R. L. (1999). Language Learning Stratgies in the Context of Autonomy, Synthesis of Finding from the International Invitational Conference on Learning Strategy Research, Teacher College. Columbia University, New York, NY.

[16] Nayikos, M. (1990). Gender-related Differences in Adult Language Learning: Socialization and Memory factors. Modren Language Journal, 74 (3), 273-287.

[17] Sheorey, R. (1999). An Examination Of Language Learning Strategy Use In The Setting Of An Indigenized Variety Of English System, 27, 173-190.

[18] Oxford, R. L. \& Naykosi, M. (1989). Variables Affecting Choice of Language Learning Strategies by University Students. The Modren Language Journal, 73, 291-300.

[19] Chang, Ching- Li \& Liu, Shu-Chen and Yi Nian (2007). A study Of Language Learning Strategies Used By College EFL Learners In Taiwan.

[20] Pezman Zare (2010). An Investigation into Language Learning Strategy and Gender Among Iranian Undergraduate Language Learners. World Applied Sciences Journal, 11 (10): 1238-1247.

[21] Rahimi Mohamed, raizi abdolmehdi \& saif shahrazad (2004). An Investigation into the Factors Affecting The Use of Language Learning Strategies by Persian EFL learners.

[22] Masoud hashemi (2011). The Impact of Gender on Language Learning Strategies of Iranian EFL Learners. International Journal of Academic Research. Vol. 3 No. 2. 2011.

[23] Shr - Chang Huang and I - Chen Chen (2004). A Study of Language Learning Strategies Used by Applied Englsih Major Students. 